\title{
KOMUNIKASI TRASENDENTAL
}

\section{Oleh: Nurhikmah}

\section{Sekolah Tinggi Agama Islam Negeri (STAIN) Parepare Email: nurhikmah@stainparepare.ac.id}

\begin{abstract}
Human ability to communicate is not limited to fellow human beings, but rather, also communicates with a Essence deemed to be God, God, or objects believed to have magical powers. Realization of human beliefs manifests slavery to God worthy of adoration through trasendental communication. Trasendental communication in Islam can be done through various media known as rituals of worship, both mandatory worship and worship of sunnah. Continuing worship is done in every day among other prayers
\end{abstract}

\section{Keywords: Transcendental, Communication, Ghaib, Prayer, Dhikr}

\section{Pendahuluan}

Komunikasi merupakan salah satu hal yang terpenting dalam realitas kehidupan. Pengaruh sebuah komunikasi sangatlah besar bagi perjalanan hidup seseorang. Kesuksesan maupun kegagalan seseorang sangat dipengaruhi oleh efek komunikasinya terhadap orang lain. Seseorang akan dipercaya atau dianggap pengkhianat, juga sangat tergantung bagaimana cara ia berkomunikasi dengan orang lain.

Komunikasi adalah proses penyampaian pesan dari seorang komunikator kepada komunikan melalui sebuah media yang menghasilkan efek. Dari definisi sederhana ini kemudian timbul pertanyaan bagaimana menjalin komunikasi dengan Allah yang secara kasat mata tidak dapat dilihat hanya bisa diyakini dan dirasakan keberadaannya. Bagaimana menghadirkan sosok komunikator atau komunikan dalam proses komunikasi ini, media seperti apa yang digunakan, dan bagaimana melihat efek yang dihasilkan dalam proses komunikasi tersebut. Hal inilah yang ingin diungkap dalam komunikasi transendental. 
Di samping itu, ditemukan bahwa kemampuan manusia berkomunikasi tidak terbatas pada sesama manusia saja, melainkan, juga berkomunikasi dengan suatu Dzat yang dianggap sebagai Tuhan, Dewa, atau benda-benda yang diyakini mempunyai kekuatan magis. Keinginan manusia untuk berkomunikasi dengan Tuhan, Dewa, atau benda-benda magis tersebut, pada dasarnya timbul dari lubuk hati manusia dengan tujuan untuk meraih kenikmatan-kenikmatan di luar nilainilai materi. Kendati demikian, cara dan bentuk manusia ketika merealisasikan keyakinannya pada Tuhan, Dewa, atau benda-benda magis lainnya, berbeda-beda sesuai dengan perbedaan dan keragaman knowledge, attitude, dan performance yang telah berkembang di tengah-tengah masyarakat bersangkutan. Hal ini tidak menutup kemungkinan adanya perbedaan penafsiran dan keyakinan pada tiap-tiap masyarakat, ketika meyakini suatu Dzat yang mereka anggap sebagai Tuhan, Dewa, atau benda-benda magis.

Realisasi keyakinan manusia terwujud penghambaan kepada Tuhan yang layak disembah melalui komunikasi trasendental. Salah satu jenis komunikasi yang tidak banyak dibahas karena bersifat abstrak, tidak mudah untuk diukur dan diamati secara empirik tapi sebenarnya justru komunikasi jenis inilah yang paling esensial dalam kehidupan di dunia karena akan sangat berpengaruh dalam kehidupan di akhirat kelak. Komunikasi tersebut merupakan komunikasi antara manusia dengan Tuhannya.

Komunikasi transendental ini dapat dilakukan melalui berbagai macam media. Dengan demikian, dalam pembahasan ini akan dibahas makna komunikasi transendental,, Model komunikasi transendentalsertakomunikasi transendental.

\section{Makna Komunikasi Transendetal}

Komunikasi yang melibatkan manusia dengan Tuhannya itulah yang sering disebut komunikasi transendental ${ }^{1}$. Manusia merupakan makhluk sosial yang tidak dapat berdiri sendiri, ia membutuhkan orang lain untuk mempertahankan eksistensinya. Manusia harus membangun hubungan horisontal

\footnotetext{
${ }^{1}$ Deddy Mulyana, Nuansa-Nuansa Komunikasi; Meneropong Politik Dan Budaya Komunikasi Masyarakat Kontemporer (Remaja Rosdakarya, Bandung: 1999) h. 49
} 
yakni dengan manusia lainnya dan vertikal dengan Tuhannya. Hubungan itu akan membawa seorang individu menjadi manusia paripurna.

Dalam resensi buku Kapita Selekta Komunikasi yang ditulis Ujang Saefullah juga dinyatakan, bahwa komunikasi transendental merupakan istilah baru dalam komunikasi yang belum banyak dikaji oleh para pakar komunikasi karena sifatnya abstrak dan transenden. Komunikasi transendental adalah komunikasi yang berlangsung antara diri kita dengan sesuatu yang gaib, bisa Tuhan-Allah, malaikat, jin atau iblis. Untuk memahami komunikasi transendental secara alamiah dapat ditelusuri lewat filsafat Islami. ${ }^{2}$

Menurut Deddy Mulyana bahwa meskipun komunikasi ini paling sedikit dibicarakan, justru bentuk komunikasi inilah yang terpenting bagi manusia karena keberhasilan manusia melakukannya tidak saja menentukan nasibnya di dunia, tetapi juga di akhirat. ${ }^{3}$ Manusia berhasil atau tidak dalam berhubungan dengan Tuhan atau bagaimana ia bisa menempati surga di akhirat tergantung pada strategi pendekatan yang dilakukannya.

Definisi lain dikemukakan oleh Hayat Padje bahwa Komunikasi transendental adalah komunikasi dengan sesuatu yang bersifat "gaib" termasuk komunikasi dengan Tuhan. ${ }^{4}$ Gaib di sini adalah hal-hal yang sifatnya supranatural, adikodrati, suatu realitas yang melampaui kenyataan duniawi semata. Wujud hal gaib yang dimaksudkan dalam agama modern yang disebut "Tuhan " atau "Allah" atau nama lain yang sejalan dengan pengertian itu. Keterbukaan kepada hal gaib merupakan keterbukaan kepada kebaikan, kepada hal yang positif dan terpuji. Kepercayaan kepada hal gaib adalah kepercayaanmanusia tentang adanya suatu kekuatan yang mengelilingi hidupnya, melebihikekuatan dunia ini yang mempengaruhi hidupnya. ${ }^{5}$

\footnotetext{
${ }^{2}$ http://promosimbiosa.blogspot.com/2011/05/kapita-selekta-komunikasi.html

${ }^{3}$ Deddy Mulyana, Nuansa-Nuansa Komunikasi; Meneropong Politik Dan Budaya Komunikasi Masyarakat Kontemporer, h. 49

${ }^{4}$ Gud Reacht Hayat Padje, Komunikasi Kontemporer: Strategi, Konsepsi, dan Sejarah (Kupang: Universitas PGRI, 2008),h.20

${ }^{5}$ Antonius Atoshoki Gea, dkk. Character Building III: Relasi Dengan Tuhan (Jakarta: Gramedia, 2004), h.7-8
} 
Secara terminologis komunikasi merupakan proses penyampaian suatu pernyataan oleh seseorang kepada orang lain. Dari pengertian ini jelas bahwa komunikasi melibatkan sejumlah orang, di mana seseorang menyatakan sesuatu kepada orang lain yang disebut dengan 'komunikasi manusia' (humancommunication) atau 'komunikasi sosial' (social communication). Komunikasi manusia sebagai singkatan dari komunikasi antar manusia dipahami sebagai komunikasi sosial atau komunikasi kemasyarakatan adalah dikarenakan hanya pada manusia-manusia yang bermasyarakat akan dapat tercipta komunikasi.

Menurut pakar komunikasi Nina W. Syam, komunikasi tradensental merupakan salah satu wujud berpikir tentang bagaimana menemunkan hukumhukum alam dan keberadaan komunikasi manusia dengan Allah swt. atau antar manusia dengan kekuatan yang ada diluar kemampuan berpikir manusia yang bersifat ilahiah dan kebenarannya dilandasi oleh rasa cinta tanpa pamrih. ${ }^{6}$

Yenrizal menggambarkan bahwa komunikasi transendental adalah realitas sosial yang masih hidup dan terpelihara sampai saat ini di berbagai daerah di Indonesia. Karenanya, pemaknaan terhadap komunikasi transendental sejatinya bukan semata perspektif agama, tetapi juga perspektif kultural. ${ }^{7}$

\section{Model Komunikasi Transendental}

Shonhadji Sholeh menyatakan model komunikasi transendental sebagai sebuah model yang diberlakukan dalam struktur simbol dan aturan proses komunikasi dalam al-Quran. Model yang dinyatakan Shonhadji Sholeh memang berada dalam ranah dan perspektif teologis, utamanya agama Islam. Menurutnya, dalam al-Quran terdapat dua model komunikasi transendental, yaitu model komunikasi vertikal dan model komunikasi horisontal. Dalam komunikasi vertikal, istilah yang digunakan adalah penurunan (inzal dan tanzil). Sedangkan

\footnotetext{
${ }^{6}$ Nani W. Syam, Model-model Komunikasi Persfektif Pohon Komunikasi, (Bandung: Simbiosa Rekatama Media, 2013), h. 126

${ }^{7}$ http://dualmode.kemenag.go.id/acis10/file/dokumen/3.Yenrizal.pdf
} 
model komunikasi horisontal istilah yang digunakan adalah penyampaian (balagh, iblagh, tabligh). ${ }^{8}$

Model-model komunikasi yang paling mendekati dalam proses komunikasi transendental adalah Model S-R, Model Aristoteles, dan Model Lasswell. Deddy Mulyana menjelaskan secara terperinci mengenai tiga model ini yakni: ${ }^{9}$

a. Model Stimulus-Respons (S-R) adalah model komunikasi paling dasar. Model ini dipengaruhi oleh disiplin psikologi, khususnya yang beraliran behavioristik, dan menunjukkan komunikasi sebagai sebuah proses “aksireaksi” yang sangat sederhana. Jadi model S-R mengasumsikan bahwa kata-kata verbal misalnya ayat-ayat dalam al-Qur'an dan isyaratisyarat alam akan merangsang seorang manusia untuk melakukan tindakan atau respons tertentu.

Respons yang muncul seperti melaksanakan dan menjauhi apa yang dilarang dan diperintahkan, respons berupa rasa takjub, terpana bahkan terharu melihat berbagai keagungan ciptaan Allah. Proses ini dapat bersifat timbal balik dan mempunyai banyak efek. Setiap efek dapat mengubah tindakan komunikasi berikutnya.

b. Model Aristoteles adalah model komunikasi paling klasik, yang sering juga disebut model retoris. Aristoteles mengemukakan tiga unsur dasar proses komunikasi ini, yaitu pembicara, pesan, dan pendengar. Dalam komunikasi transendental, manusia sebagai hamba terkadang menjadi pembicara atau komunikator, yang secara sadar melakukan zikir sesuai dengan petunjuk zikir yang telah dipelajarinya atau doa-doa yang dianggap bagus sehingga bisa dikabulkan oleh Allah. Zikir atau doa itu tidak hanya disampaikan begitu saja, tapi melalui berbagai strategi untuk mendekatkan diri sedekat mungkin dengan Allah yakni berusaha untuk khusyuk.

\footnotetext{
${ }^{8}$ Chusmeru, Komunikasi Transendetal dan Kearifan Lokal dalam Kesenian Tradisonal Banyuman, t.d. h. 165

${ }^{9}$ Deddy Mulyana, Ilmu Komunikasi Suatu Pengantar ( Bandung: Remaja Rosdakarya, 2001 ), h. 132-136.
} 
c. Model komunikasi Lasswell berupa ungkapan verbal, yakni: Who says what, in which channel, to whom, with what effect. Model Lasswell sering diterapkan dalam komunikasi massa, namun juga bisa sejalan bila dipakai sebagai model komunikasi transendental.

Unsur sumber who adalah partisipan komunikasi transendental sendiri yakni Allah dan Manusia. Unsur pesan (says what) adalah apa yang dikatakan Allah melalui ayat-ayat al-Qur'an dan ayatayat yang disaksikan lewat ciptaan Allah. Juga pesan yang diucapkan manusia saat shalat, berzikir, berdoa atau bentuk ibadah lainnya. Unsur saluran (in which channel), bila pesan dari Allah maka al-Qur'an bisa jadi saluran yang menyampaikan pesan-pesan Allah dan bila pesan dari manusia maka salurannya adalah sesuatu yang bersifat abstrak yang ada dalam diri setiap individu, yang hanya bisa dirasakan atau diketahui oleh manusia yang melakukan proses komunikasi transendental dengan Allah. Unsur penerima (To whom) sama dengan sumber, di mana Allah dan manusia berfungsi timbal-balik sebagai sumber dan penerima. Sementara unsur pengaruh (with what effect) jelas berhubungan dengan akibat yang ditimbulkan pesan komunikasi. Bagi manusia efek yang dirasakan adalah doa yang terkabul atau ketenangan batin, sedangkan pesan Allah bisa melahirkan kepatuhan dan ketundukan manusia dalam melaksanakan perintah dan menjauhi larangan.

Sedangkan perspektif Nani W. Syam, model komunikasi transendental perspektif Islam yakni : ${ }^{10}$

a. Ruh.

Ruh merupakan sesuatu yang abstarak ada dalam rongga biologis pembawa kehidupan. Ruh secara khusus hanya dibahas al-Gazali (pendekatan tasawuf falsafi), memiliki kemampuan mengetahui dan mencerap hakikatnya tidak dapat dibahas/dipahami. Sebagaimana QS. AlIsra' : 85

\footnotetext{
${ }^{10}$ Nani W. Syam, Model-model Komunikasi Persfektif Pohon Komunikasi, h. 128
} 


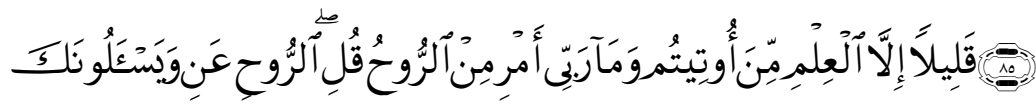

Terjemahnya:

Dan mereka bertanya kepadamu tentang roh. Katakanlah: "Roh itu Termasuk urusan Tuhan-ku, dan tidaklah kamu diberi pengetahuan melainkan sedikit".

b. Nafs

Nafs bermaknaamarah dan ambisi (syahwah)serta jati diri manusia memiliki potensi mengetahui.Sedangkankajian al-Gazali diadopsi dari Sigmund Freud nafsterdiritigakategoriyakni:

1) id (Nafs Amarah). Qs. Yusuf 12: 53

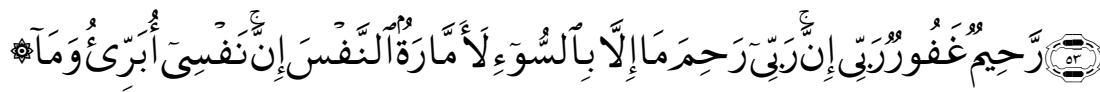

Terjemahnya:

Dan aku tidak membebaskan diriku (dari kesalahan), karena Sesungguhnya nafsu itu selalu menyuruh kepada kejahatan, kecuali nafsu yang diberi rahmat oleh Tuhanku. Sesungguhnya Tuhanku Maha Pengampun lagi Maha Penyanyang.

2) ego (nafs lawwamah) Qs. Al-qiyamah 75: 2,

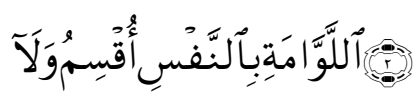

Terjemhanya:

Dan aku bersumpah dengan jiwa yang Amat menyesali (dirinya sendiri)

3) super ego (nafs mutmainnah) Qs. alfajr 89: 27

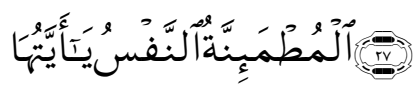

Terjemahnya:

Hai jiwa yang tenang. 
b. Aql

Aql dapat diartikan pengetahuan tentang segala sesuatu yang bertempat dihatidansesuatu wadah yang menampung pengetahuan. Al-Gazali memandang akal sebagai wadah bukan sentra dari proses berpikir. Dalam kajian filosof Islam, akal adalah sentra proses berpikir. Ini ditemukan dalam kajian al-Kindi dan al-Farabi, tentang akal pertama hingga akan ke dua belas. Ibnu Thufail memandang kekuatan akal dapat mengenal hakikat Tuhan.

\section{Proses Komunikasi Trasendental}

Proses yang dilewati selama ritual ibadah berlangsung merupakan bagian dari komunikasi yang disebut proses komunikasi transendental. Dalam khazanah ilmu komunikasi, komunikasi transendental merupakan salah satu bentuk komunikasi di samping komunikasi antarpersona, komunikasi kelompok, komunikasi organisasi, komunikasi antar budaya, komunikasi verbal, komunikasi non-verbal dan komunikasi massa. Namun komunikasi transendental tidak pernah dibahas luas. Cukup dikatakan bahwa komunikasi transendental adalah komunikasi antara manusia dan Tuhan. Komunikasi manusia dengan Tuhan merupakan proses komunikasi yang perlu ditelaah lebih mendalam untuk diwujudkan secara konkrit dalam bentuk pemaparan yang komprehensif mengenai bentuk komunikasi ini Manusia beribadah kepada Allah mengenal Allah melalui dua cara yakni: ${ }^{11}$ Ayat-ayat Kauniyah - alam semesta ciptaan Allah swt dan ayatayat Quraniyyah - firman Allah dalam al-Qur'an. Keduanya merupakan perintah dan larangan Allah swt. yaitu apa yang boleh dilakukan dan apa yang tidak boleh dilakukan sehingga pemahaman makna/simbolik firman Allah swt. untuk mencapai tujuan hidup dan Ridha Allah swt.

Sedangkan komunikasi trasendental melalui konsep hati dalam komunikasi spiritual. Sembilan puluh sembilan Asmaul Husna sifat-sifat Allah swt. merupakan komunikasi yang disampaikan Allah swt. kepada ruh dialam rahim saat usia kandungan empat bulan dengan proses suara hati manusia yang

\footnotetext{
${ }^{11}$ Nani W. Syam, Model-model Komunikasi Persfektif Pohon Komunikasi, h. 133
} 
paling dalam, fitrah manusia/kesucian diri manusia, kesadaran manusia akan suara hati yang universalmelandasi komunikasi spiritual manusia dengan Allah swt. ${ }^{12}$

Pemahaman konsep komunikasi spiritual yang meliputiaspekintelektual, emosionaldan spiritual itusendiri. ${ }^{13}$

a. Intektual Quotient (IQ) komunikasinya melalui proses saluran hati kesuara hati Spiritual Quotient ke sifat Allah mendapatkan Kebenaran hakiki

b. Emotional Quotient (EQ) komunikasinya melalui proses saluran Mata ke Intelektual Quotient dengan logika mendapatkan penjabaran konkrit

c. Spiritual Quotient (SQ) komunikasinya melalui proses telinga ke mentalitas Emotional Quotient melalui lingkungan untuk mendapatkan keberhasilan mental.

Perpaduan proses IQ, EQ dan SQ dapat mencapai keberhasilan spritual dan trasendental proses komunikasi yang efektif, sesuai kehendek Allah swt. manusia dan alam merupakan proses komunikasi.

\section{Media Komunikasi Transendental dalam Islam}

Komunikasi trasendental dalam shalat dapat diibaratkan bahwa Tuhan adalah sebagai penerima (communican), sedangkan pelaku bertindak sebagai pengirim pesan (communicator), sumbernya (source) adalah dari para pelakunya atau kejadian yang dialami, medianya (channel) adalah shalat atau doa kita, (effect) adalah ketenagngan jiwa yang akan kita dapatkan atau simbol-simbol dan tanda-tanda lainnya tang tuhan kirimkan kepada kita. ${ }^{14}$

Komunikasi trasendental dalam Islam dapat dilakukan melalui berbagai macam media yang dikenal dengan ritual ibadah, baik ibadah wajib maupun ibadah sunnah. Ibadah-ibadah yang berkesinambungan dilakukan dalam setiap hari antara lain shalat.

${ }^{12}$ Nani W. Syam, Model-model Komunikasi Persfektif Pohon Komunikasi, h. 134

${ }^{13}$ Nani W. Syam, Model-model Komunikasi Persfektif Pohon Komunikasi, h. 135

${ }^{14}$ Vivi Yuliani et.al, Studi Analisis Komunikasi Trasendental Ibdah Shalat dan Pemaknaannya dari Persfektif Verbal dan Non Verbal, Proseding Komunikasi Penyiaran Islam Vol. 2, No. 1, 2016, h. 45 
Shalat menurut bahasa ialah doa. Karena itulah membaca doa untuk Nabi dinamakan shalat atau sholawat ${ }^{15}$. Sementara menurut syara' shalat adalah hubungan antara hamba dengan Tuhannya. Allah berfirman dalam Qs. Thaha ayat 14 :

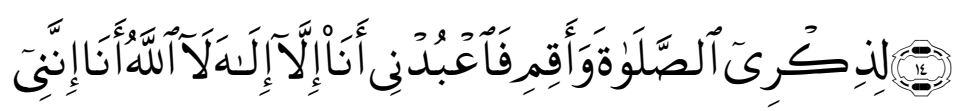

Terjemhanya:

Sesungguhnya aku ini adalah Allah, tidak ada Tuhan (yang hak) selain Aku, Maka sembahlah aku dan dirikanlah shalat untuk mengingat aku.

Melalui ayat tersebut jelaslah bahwa shalat yang baik dan benar akan mengantar seseorang mengingat kebesaran Allah dan mengantarnya untuk melaksanakan perintah-perintah-Nya dan menjauhi larangan-Nya ${ }^{16}$.

Abu Ahmadi mengatakan bahwa shalat ialah sekumpulan doa, aktivitasaktivitas biologis dan psikologis yang telah ditentukan syarat rukunnya yang diawali dengan takbiratul ihram dan diakhiri dengan salam. Hal ini memberikan simbol keharmonisan hablumminallah dengan takbir dan hablumminannas melalui salam. Sehingga seorang musholli diharapkan setelah dia berhasil membangun hubungan baik dengan Allah mampu menjalin hubungan baik dengan manusia. $^{17}$

Shalat merupakan suatu aktivitas jiwa (soul) yang termasuk dalam kajian ilmu psikologi transpersonal, karena shalat adalah proses perjalanan spiritual yang penuh makna yang dilakukan seorang manusia untuk menemui Tuhan Semesta Alam $^{18}$. Gerakan-gerakan shalat adalah tugas biologis, unsur-unsur pokok jasmani harus digerakkan, dikembangkan, punya nilai kesehatan, adab dan penghormatan

\footnotetext{
${ }^{15}$ Tengku Muhammad Hasbi Ash-Shiddieqy, Kuliah Ibadah(Semarang: Pustaka Riski Pt2000 :130).

${ }^{16}$ Quraish Shihab, Tafsir al-Mishbah; Pesan, Kesan, dan Keserasian al-Qur'an, (Jakarta: Lentera Hati, 2004), h. 284

${ }^{17}$ Abu Ahmadi, Mutiara Isra' Mi'raj (Jakarta: Bumi Aksara, 1995), h. 76

${ }^{18} \mathrm{Abu}$ Sangkan, Pelatihan Shalat Khusyu' (Jakarta: Yayasan Shalat Khusyu' dan Manajemen Masjit BAITUL Ihsan Bank Indonesia, 2008). H. 7
} 
pada Allah. Ucapan-ucapan (doa-doa) dalam shalat, sejak takbiratul ihram hingga salam merupakan kalimat suci sebagai lambang penghormatan dan penghargaan kepada Allah swt. Ritual ini kita lakukan setiap hari lima kali, sehingga rasa dan hubungan batin kita tetap terjaga secara rapi dan teratur, agar hubungan kepada Allah semakin kuat.

Secara lahiriah proses komunikasi vertikal dalam shalat ini tampak bersifat satu arah, namun pada hakekatnya adalah komunikasi dua arah, sebab shalat merupakan dialog lewat pujian-pujian dan permohonan kepada-Nya. Ucapanucapan, bacaan-bacaan dan tata cara berkomunikasi telah ditentukan formatnya oleh Allah lewat perintah- Nya kepada Nabi saw. tatkala melakukan perjalanan transendental yaitu Isra' Mi'raj.

Secara makro, saat shalat terjadi komunikasi dua arah antara manusia dengan penciptanya, meski secara mikro yang dirasakan oleh orang yang melaksanakan perintah shalat adalah komunikasi intra pesona (bukan antar pesona), artinya ia bicara dengan dirinya sendiri. Komunikasi adalah proses penciptaan makna antara dua pihak atau lebih lewat penggunaan simbol-simbol atau tanda-tanda. Oleh karena itu, komunikasi yang terjalin saat shalat dengan partisipan manusia dengan Allah ${ }^{19}$ merupakan komunikasi transendental.

Selanjutnya, keberhasilan atau efektifitas komunikasi berbanding lurus dengan derajat kesamaan atau kesesuaian makna yang tercipta di antara para pesertanya. Komunikasi disebut efektif bila makna yang tercipta relatif sama atau hasil komunikasinya relatif sesuai dengan yang diinginkan komunikator. Namun pada dasarnya tidak ada komunikasi yang seratus persen efektif karena tidak ada dua manusia yang mempunyai pengalaman yang persis sama. Inti dari proses komunikasi adalah persepsi, yakni proses internal dengan mana manusia memilih, mengevaluasi, mengorganisasikan dan menafsirkan rangsangan dari sekitarnya. ${ }^{20}$

Rangsangan bisa berbentuk lambang-lambang, tanda-tanda atau kejadiankejadian. Jika persepsi kita tidak akurat, tidak mungkin komunikasi kita efektif, persepsilah yang menentukan kita memilih pesan tertentu dan mengabaikan yang

${ }^{19}$ Deddy Mulyana, Nuansa-Nuansa Komunikasi, Bandung: Remaja Rosdakarya, 1999) h.

${ }^{20}$ Deddy Mulyana, Nuansa-Nuansa Komunikasi, h. 49 
lain, memberi makna tertentu pada pesan tersebut dan tidak memberi makna lain. Karena tidak ada manusia yang mempunyai pengalaman yang persis sama, maka tidak ada dua manusia yang mempunyai persepsi yang sama terhadap suatu rangsangan.

Agar dapat mencapai tujuan relatif yang kita inginkan, kita harus mempelajari lambang-lambang tersebut. Ajaran Islam mengenal lambanglambang atau tanda-tanda Allah tersebut dengan ayat-ayat Allah ${ }^{21}$. Al-Quran dan hadis Nabi adalah media massa cetak yang sakral, yang memuat perintah-perintah dan larangan-larangan $\mathrm{Allah}^{22}$. Apabila kita ingin disebut sebagai partisipan komunikasi transendental yang baik, maka kita harus mempersepsi secara akurat lambang-lambang yang difirmankan Allah. Seperti ketika Allah memerintahkan agar umat Islam mengerjakan shalat, perintah ini tertulis dalam Qs. an-Nuur ayat 56:

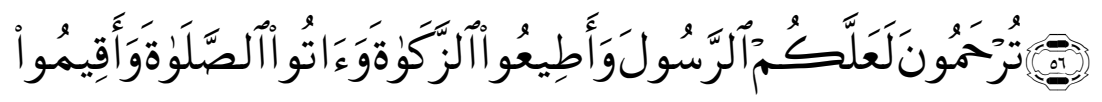

Terjemahnya:

"Tetaplah mengerjakan shalat, tunaikanlah zakat, dan taatlah kepada Rasul, supaya engkau mendapat rahmat."

Keberhasilan komunikasi kita dengan Allah, sebagaimanakeberhasilan komunikasi kita kepada manusia, juga ditentukan olehketepatan mempersepsi kita sendiri: siapakah kita, apa tujuan hidupkita di dunia dan mau kemana kita setelah hidup ini? Inti konsep dirimanusia di hadapan Allah adalah bahwa manusia itu diciptakan olehAllah untuk menyembah-Nya, sebagaimana disebutkan dalam Qs.adz-Dzariyaat ayat 56: "Dan Aku tidak menciptakan jin dan manusiamelainkan supaya mereka menyembah Aku”.

Allah sebagai mitra komunkasi kita yang harus kita sembah tidak mungkin mempersepsi kita secara keliru dan tidak mungkin memberi tanda-tanda yang menyesatkan kita. Tanda-tandanya begitu jelas dan jernih dan ada dimana-mana, kitalah yang harus peka mengenal dan secara tepat mempersepsi tanda-tanda-Nya.

\footnotetext{
${ }^{21}$ Deddy Mulyana, Nuansa-Nuansa Komunikasi, h. 51

${ }^{22}$ Muis, Komunikasi Islam, Bandung: Remaja Rosdakarya, 2001) h. 44
} 
Kekeliruan mempersepsi tanda-tanda-Nya itu akan berakibat fatal bagi kita, jauh lebih fatal daripada akibat kekeliruan mempersepsi lambang-lambang manusia. Akibat kekeliruan mempersepsi ini adalah hukuman dari Allah yaitu dihukum di neraka yang panas membara. Allah menyebut orang yang melakukan kekeliruan ini sebagai binatang, bahkan lebih sesat lagi, karena tidak mau menggunakan mata mereka untuk melihat dan tidak mau menggunakan telinga mereka untuk mendengar, Allah berfirman dalam Qs. al-A'raf ayat 179: "Sesungguhnya telah kami sediakan untuk penghuni neraka itu banyak jin dan manusia"

\section{Penutup}

\section{Kesimpulan}

Dari pembahasan mengenai komunikasi trasendental, dapat disimpulkan berdasarkan rumusan masalah sebagai berikut:

Makna komunikasi trasendental adalah komunikasi yang berlangsung antara diri kita dengan sesuatu yang gaib, bisa Tuhan-Allah, malaikat, jin atau iblis atau memaknai sebagai realitas sosial yang masih hidup dan terpelihara sampai saat ini di berbagai daerah di Indonesia. Jadi komunikasi trasendental tidak hanya dipandang dari sudut pandang agama tetapi kultural.

Model-model komunikasi yang bisa sejalan dengan proses komunikasi transendental adalah Model S-R, Model Aristoteles, dan Model Lasswell. Model S-R menekankan pada adanya stimulus dan respons yang disampaikan pada saat bekomunikasi antara komunikator dan komunikan dalam hal ini Allah dan manusia sebagai partisipan komunikasi transendental. Model Aristoteles menekankan pada pembicaraan yang retoris dan persuasif dengan tiga komponen di dalamya yakni pembicara, pesan, dan pendengar. Model ini lebih dekat dengan model komunikasi seorang hamba saat shalat, berzikir, berdoa, atau ibadah lainnya. Model Lasswell menekankan pada siapa yang berbicara, apa yang dibicarakan,menggunakan saluran apa, kepada siapa dan apa efeknya. Model ini lebih menegaskan pada unsur-unsur komunikasi yang berlaku umum

Komunikasi trasendetal dalam shalat dapat diibaratkan bahwa Tuhan adalah sebagai penerima (communican), sedangkan pelaku bertindak sebagai 
pengirim pesan (communicator), sumbernya (source) adalah dari para pelakunya atau kejadian yang dialami, medianya (channel) adalah shalat atau doa kita, (effect) adalah ketenagngan jiwa yang akan kita dapatkan atau simbol-simbol dan tanda-tanda lainnya tang tuhan kirimkan kepada kita.

Komunikasi trasendental dalam Islam dapat dilakukan melalui berbagai macam media yang dikenal dengan ritual ibadah, baik ibadah wajib maupun ibadah sunnah. Ibadah-ibadah yang berkesinambungan dilakukan dalam setiap hari antara lain: Shalat, Sebagai mi'rajul mukmin, shalat yang kita lakukan mestinya betul-betul mampu membuahkan kesadaran akan makna taqarrub kepada Allah yang tidak ada hijab diantara seorang hamba dengan Tuhannya. Sehingga akan membuat shalat kita lebih produktif sebagaimana fungsi yang sesungguhnya yaitu dzikrullah dan tanha an al-fakhsya wa al-munkar.

Langkah yang paling tepat agar komunikasi transendental melalui shalat ini berhasil adalah dengan shalat secara khusyuk. Khusyuk bermakna kesadaran penuh akan kerendahan kehambaan ('ubudiyah) diri kita sebagai manusia di hadapan keagungan Rububiyyah (Ketuhanan). Sikap khusyuk ini timbul sebagai konsekuensi kecintaan sekaligus ketakutan kita kepada Zat Yang Maha Kasih dan Maha Dahsyat ini. Sebagai implikasinya, orang yang memiliki sikap seperti ini akan berupaya memusatkan seluruh pikiran kepada Kehadiran-Nya dan membersihkannya dari apa saja yang selain Allah. Tidak bisa tidak ini berarti hadirnya hati. Tanpa kehadiran hati, shalat kehilangan nilainya. Rasulullah bersabd: "Shalat yang diterima adalah sekadar hadirnya hati."

\section{Daftar Pustaka}

Ahmadi, Abu. Mutiara Isra' Mi'raj. Jakarta: Bumi Aksara, 1995

Chusmeru, Komunikasi Transendetal dan Kearifan Lokal dalam Kesenian Tradisonal Banyuman.

Gea, Antonius Atoshoki, dkk. Character Building III: Relasi Dengan Tuhan Jakarta: Gramedia. 2004.

http://dualmode.kemenag.go.id/acis10/file/dokumen/3.Yenrizal.pdf 
http://promosimbiosa.blogspot.com/2011/05/kapita-selekta-komunikasi.html

Muis, Komunikasi Islam, Bandung: Remaja Rosdakarya, 2001.

Mulyana, Deddy. Ilmu Komunikasi Suatu Pengantar. Bandung: Remaja Rosdakarya, 2001

Mulyana.,Deddy Nuansa-Nuansa Komunikasi; Meneropong Politik Dan Budaya Komunikasi Masyarakat Kontemporer, Remaja Rosdakarya, Bandung: 1999

Padje,Gud Reacht Hayat. Komunikasi Kontemporer: Strategi, Konsepsi, dan Sejarah. Kupang: Universitas PGRI, 2008

Sangkan,Abu. Pelatihan Shalat Khusyu'. Jakarta: Yayasan Shalat Khusyu' dan Manajemen Masjit BAITUL Ihsan Bank Indonesia, 2008.

Shiddieqy, Tengku Muhammad Hasbi Ash-. Kuliah Ibadah. Semarang: Pustaka Riski, 2000.

Shihab,Quraish Tafsir al-Mishbah; Pesan, Kesan, dan Keserasian alQur'an,Jakarta: Lentera Hati, 2004

Syam, Nani W.Model-model Komunikasi Persfektif Pohon Komunikasi ,Bandung: Simbiosa Rekatama Media, 2013

Yuliani, Vivi. et.al, Studi Analisis Komunikasi Trasendental Ibdah Shalat dan Pemaknaannya dari Persfektif Verbal dan Non Verbal, Proseding Komunikasi Penyiaran Islam Vol. 2, No. 1, 2016. 